\title{
Nota sobre la ruta gastronómica del cuy en el Valle de Yucay (Cuzco-Perú)
}

\section{Lita Román}

El cuy tiene en el Perú muy distintas formas de preparación. Varias regiones cuidaron su presentación. En Arequipa, por ejemplo, prima el cuy chactado, en Moquegua, el cuy frito. En la zona central, en Huancayo, hay un cuy colorado preparado en olla a fuego lento. Como suele ocurrir con muchos otros productos, el cuy soporta variaciones locales y se adapta a las circunstancias geográficas y culturales. En el Guzco, las fiestas del Corpus Christi se celebran con cuy y se regan con chicha y cerveza. Abundantes potajes y en medio de ellos el cuy bien horneado con las hierbas que le dan gusto y olor. En un pueblito al sur de Cuzco, donde brillan las piedras de la construcción incaica de Tipón y se guardan los secretos coloniales de Oropesa, se desarrollaron el gusto y el sabor del cuy horneado.

\section{El paisaje turístico del Valle de Yucay (Cuzco)}

El Valle de Yucay tiene varias orientaciones turísticas. La orientación sur que sigue la ruta hacia el Lago Titicaca, no es muy frecuentada. El tren carga con los visitantes que se dirigen hacia Puno. Y los pueblos que se ubican en la ruta quedan en el olvido. Los pocos visitantes que se atreven a visitar la región van hacia Urcos y buscan la capilla de Andahuayllilas y Huaro. No muy lejos se ubica Choquepata, en el distrito de Oropeza de la provincia de
Quispicanchis. La población de Choquepata es fiel guardián del Parque Arqueológico de Tipón, más conocido con el nombre de Tipón, denominación que utilizaremos de aquí en adelante.

Los habitantes de Tipón ya eran partícipes del turismo en las últimas décadas, pero sólo como espectadores de las actividades organizadas en las ciudades del Cuzco y Lima, e. incluso en el extranjero, cuando los paquetes turísticos prefabricados incluían al Parque Arqueológico de Tipón. El beneficio para los lugareños era nulo.

Cuentan las leyendas que Tipón fue la morada casa del inca Yaguar Guaca o Yawar Waqaj. Las monumentales ruinas arqueológicas de Tipón con sus fuentes y frías aguas, han sido hasta ahora el principal atractivo turístico de la región. También la belleza de los campos del valle servian de pretexto para visitas dominicales familiares y encuentros y la fama del buen pan de Oropesa que sirvió a muchos para visitar el pueblo acabó también por reactivar una tradición que había quedado en el olvido: la preparación tradicional del cuy. Hombres y mujeres echaron mano a la obra en los últimos años y Choquepata es conocido como el lugar donde el cuy se hornea y se sirve con los sabores más exquisitos de la región.

Es importante hacer notar que, como consecuencia del incremento de comensales 
atraidos por la exquisitez de los cuyes al horno, se intensificó la presencia de ávidos comerciantes arequipeños que ofrecian este tipo de roedores criados en Arequipa: cuyes de buen peso y "buen ver", denominados a propósito de ello "maurominas", ocupando buena parte del espacio comercial en Tipón. Sin embargo, esta oferta ha ido decreciendo debido a la exigencia por parte del turista, fundamentalmente el de origen regional, de un cuy preparado al horno con los ingredientes típicos y de la manera tradicional, es decir con un roedor criado en la zona con alimentos locales. Hay, pues un reconocimiento y evidente preferencia por las formas tradicionales de crianza y preparación del cuy, lo cual hace pensar en la posibilidad de un manejo gastronómico a partir de este producto que sea sostenido y que beneficie a la comunidad receptora.

Hasta fines de la década del noventa del siglo pasado los habitantes de Tipón se encontraban en una terrible encrucijada debido a que se trata de una zona agrícola ganadera y hubo cierta inquietud frente a la posibilidad de vivir del turismo. Esta agricultura ha estado tradicionalmente vinculada con el trabajo familiar, con poco apoyo y asesoría técnica -situación compartida por muchas otras regiones del país-. El agricultor no sabe qué sembrar y el técnico no se siente seguro de aconsejar a pesar de sentir ineficaz el manejo tradicional de la producción. Es el caso de las empresas de apoyo a las actividades agrarias que han reducido el tamaño de sus ventas a lo largo de los años. Además existen dificultades para la adaptación de las modernas técnicas de gestión, así como la capitalización necesaria para acceder a tamaños que permitan una mínima competitividad y la diversificación de la producción. Todo ello no es sino la expresión de una crisis generalizada que afecta a todos los sectores socioeconómicos del medio rural y urbano en el Perú.

Sin embargo, la iniciativa de los habitantes de Tipón hizo que se pudiera hacer uso turístico de una actividad que tradicionalmente se ha realizado en la región. Se trata de una zona atrayente para el turista regional, nacional y extranjero que quiere conocer a las gentes del lugar, así como su cultura, gastronomía, cos- tumbres y sus relaciones con el medio. La mayoría de los habitantes de la zona se mejoró con el desarrollo de esta actividad gastronómica. Puede mencionarse la instalación de los criaderos, la obtención de alimentos para roedores, la especialización en la elaboración del plato, la construcción del horno de tipo artesanal, así como el transporte organizado. Todo ello implica que la producción económica y turística queda en la zona, repercutiendo favorablemente en el pueblo de Tipón en niveles como la infraestructura, ya que con el objetivo de brindar una mejor atención al turista se están construyendo alojamientos. Pero esta proyección debe enfocarse en concordancia con el paisaje natural para evitar la segmentación paisajística que alteraría el entorno.

\section{El cuy en los Andes}

El cuy es una especie nativa del Perú (cavia Porcellus) denominada cuy criollo. Es una de las maravillas que este país ha regalado a la humanidad para su beneficio y mejoría, gala y contentamiento. Posiblemente los primeros pobladores del Cuzco se alimentaron de este roedor. Siglos después la carne de cuy junto a la del venado estuvo presente en la mesa de los conquistadores españoles. Este animalito fue llevado a Europa entre cojines cual preciosa joya, recibió el homenaje de los sabios comilones, fue observado, estudiado y degustado. Los médicos a la par que los cocineros se apoderaron de él; mientras éstos inventaban nuevas salsa que lo acompañaran, aquellos le inoculaban todos los males del mundo, como recuerda el "Corregidor". Ahora es un animal casi universal, de múltiples usos: alimento, mascota, objeto experimental. En el Perú el primero de ellos es el que por tradición prima debido a su valor nutritivo frente a otras especies.

En la región andina la crianza del cuy se realiza en el nivel familiar, sobre la base de insumos y mano de obra disponibles en le hogar. Tradicionalmente esta tarea ha sido efectuada por mujeres y niños.

\section{Preparación del cuy al horno en la región de Tipón, Cuzco.}

Se sacrifica al animal apretándole el cuello con el dedo pulgar a la altura de la médula. Se le 
deja enfriar por cinco minutos y luego se le coloca en agua hirviendo para poder pelarlo con facilidad. Después de dos o tres incursiones en agua caliente y agua fría, consecutivamente, se le puede trabajar sin dificultad. Se lava y limpia la piel ayudándose con hojas de afeitar. Se le abre luego para extraer las tripas y la sangre en el interior del animal sirve para bañarlo y dejarlo en oreo durante treinta minutos. Pasado este tiempo se le incorpora el "menjunge".

El menjunge, que es lo que le dará el sabor característico, se prepara con ajos en cantidad considerable, comino entero, aji amarillo y wacatay. También común poco de chicha de jora y sal al gusto. Los ingredientes son molidos en el mortero de piedra o batán. Este preparado deberá cubrir al cuy por dentro y por fuera. Una vez que el animal está totalmente embadurnado se le coloca wacatay sin moler en el interior y se le deja reposar por treinta minutos antes de ponerlo al horno caliente por un lapso de 20 ó 30 minutos. Este platillo de cuy al horno se presenta con tres papas horneadas (de la variedad huayro) y aji típico (llatán). En algunas cuyerías se prefiere el rocoto relleno o el ta-llarín al horno como acompañantes; sin embargo las preferencias van por el clásico cuy con papas horneadas y tullán, que es la panza del cuy rellena con papitas cuadradas y otros condimentos.

En cuanto al horno artesanal lo que se ha podido observar es que un área de $1.70 \times$ $1.70 \mathrm{~m}$. Se hace un hoyo y se levantan muros de adobe de $0.70 \mathrm{~m}$ de altura. Queda un vacio central: un cuadrado bastante amplio de $1 \mathrm{~m} 2$. Este huecos rellenado de la siguiente manera: una primera capa con piedra chancada; una segunda capa con guano de cuy de corral; una tercera capa con vidrio molido; una última capa con sal común o sal yodada. Ésta constituye la base sobre la cual se levantará el horno arte sanal y se construye así para que el calor pueda concentrarse y el horno no se enfrié fácilmente. Esta superficie es revestida por una capa de ladrillo pastelero bien acabado para mantener la limpieza. Es sobre este piso que se colocarán los cutes. Por encima se levanta el techo en forma de bóveda con adobes pequeños de 0.26 $\times 0.09 \mathrm{~m}$.

La información proporcionada por los lugareños es bastante completa en lo que corresponde a la construcción de los hornos artesanales. El mortero que se utiliza para la unión de los adobes tiene sus peculiaridades como el uso de los cabellos ( 3 ó 4 kilos) para el metro cúbico de arcilla y 5 bolsas de sal. Estos ingredientes se mezclan bien (se pisan) y se deja listo el preparado un día antes de ser utilizado en la construcción del horno. Esta construcción sigue un patrón único y debe tener un acabado hecho sobre la base de arcilla, tierra y paja que consiga fortalecerlo y darle un buen terminado. Existe otro tipo de horno, de dos pisos, en donde el primero hace las veces de fogón y el segundo sirve para disponer los cuyes. Las medidas de los hornos varían de acuerdo con el número de cuyes que se estime asar.

En la localidad de Tipón existen aproximadamente 30 cuyerías entre grandes $y$ pequeñas, según los informantes agustín Ccuro Huamán y Lino Quispe Huarca, ambos dueños de este tipo de establecimientos. Según ellos el promedio de ventas en los días sábado y domingo asciende a 70 cuyes en locales medianos y 100 en los negocios grandes. En día normal el promedio es de 30 cuyes.

Lita Román

Escuela Profesional de Gestión en Turismo y Hotelería U. Nacional José Faustino Sánchez Carrión 

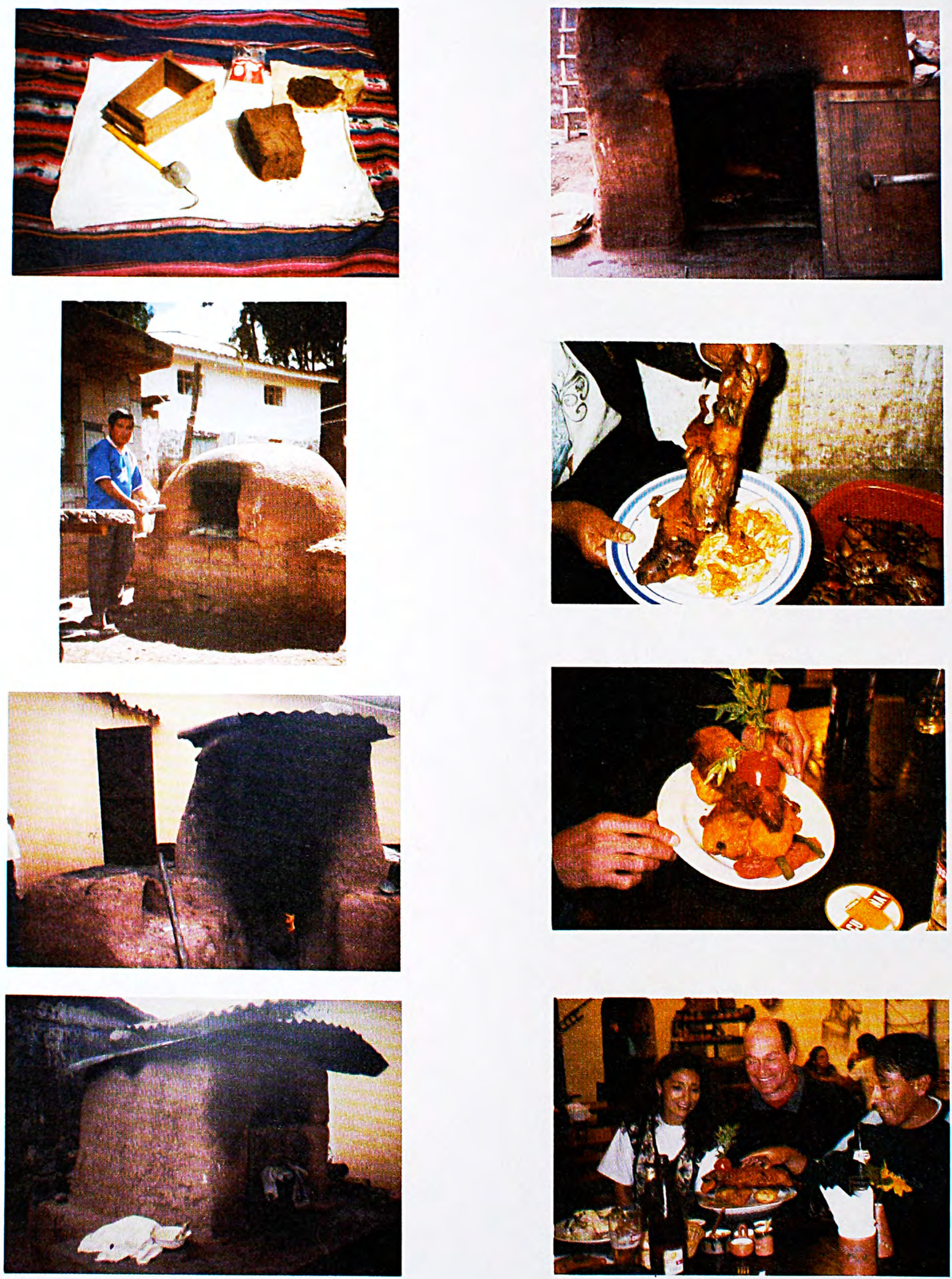
GRÁFICO 1

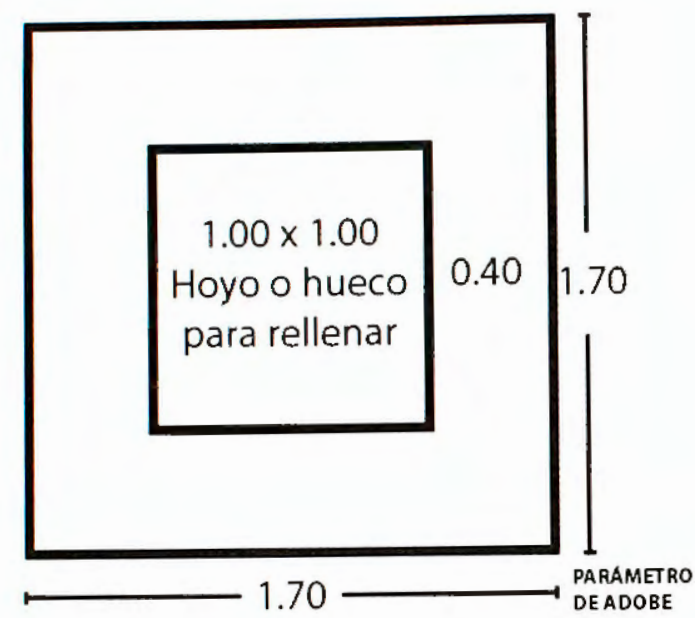

GRÁFICO 2

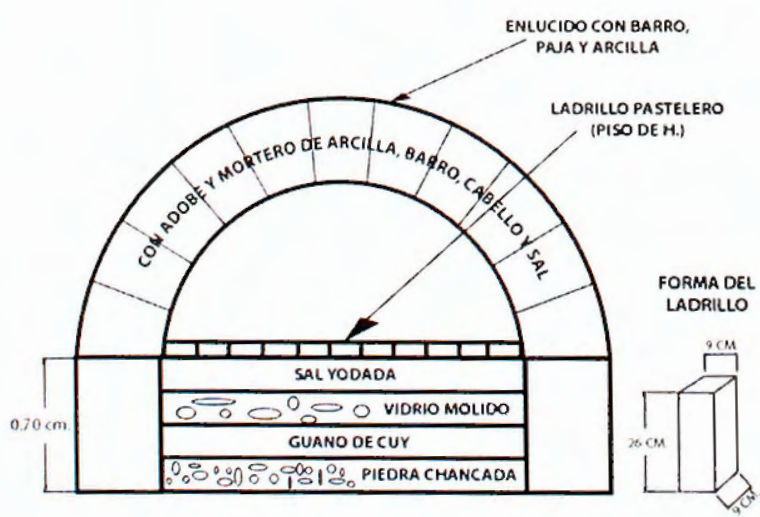

\section{GRÁFICO 3}

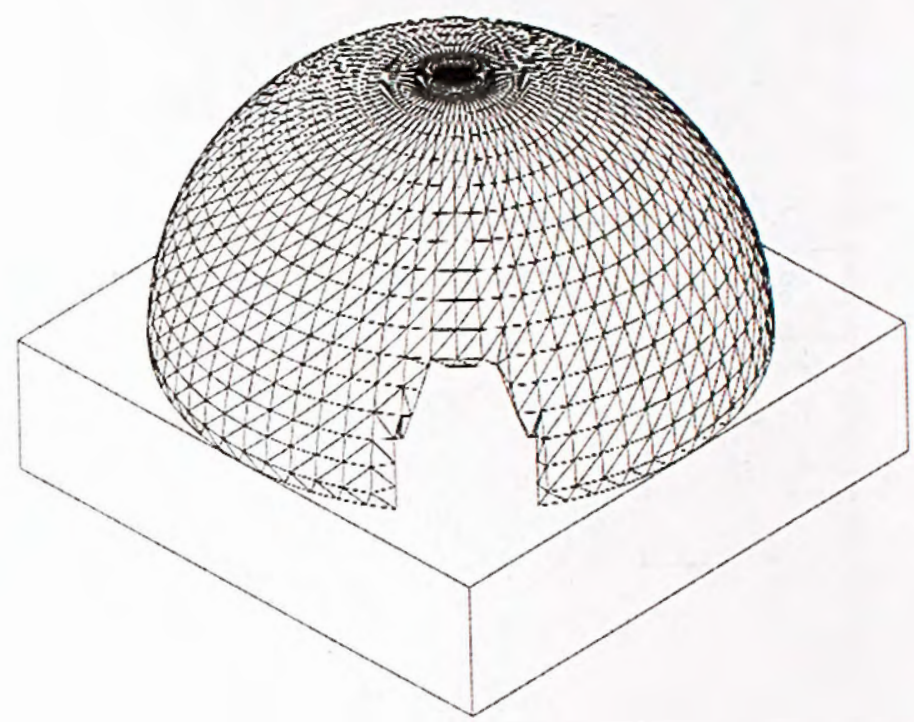

Horno

GRÁFICO 4

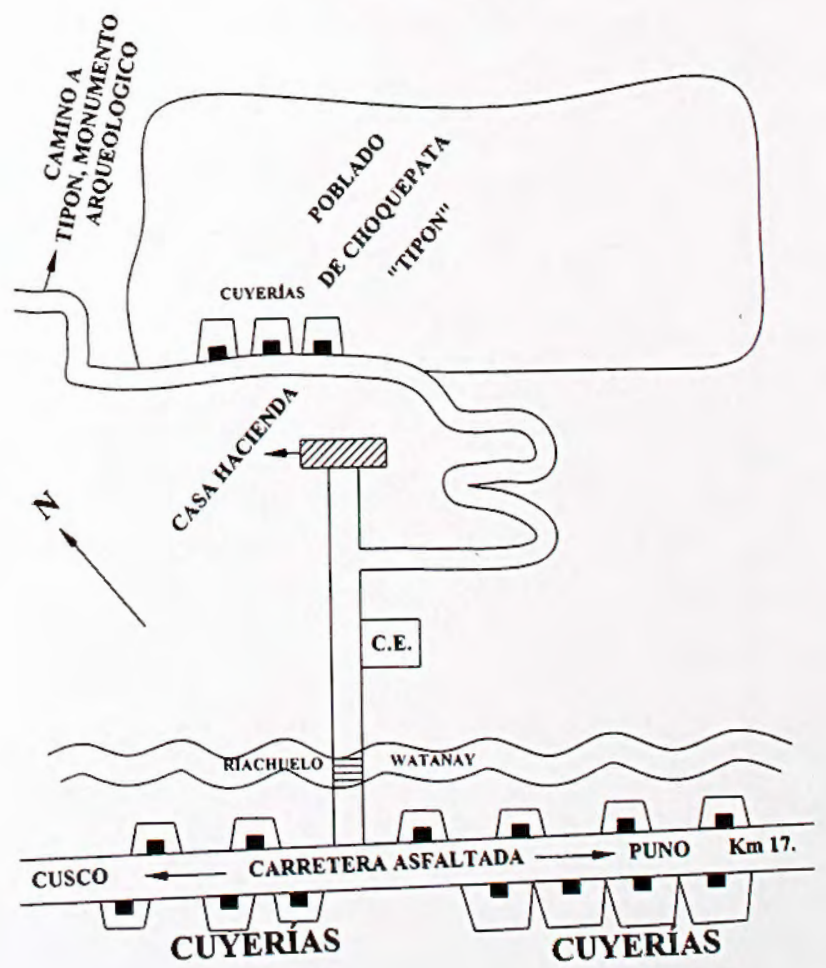

CROQUIS CUYERAAS
DE "TIPON" 